\title{
Finite-Element Analysis of Shear-Off Failure of Keyed Dry Joints in Precast Concrete Segmental Bridges
}

\author{
Rabee Shamass ${ }^{1}$; Xiangming Zhou, Ph.D., M.ASCE ${ }^{2}$; and Giulio Alfano, Ph.D. ${ }^{3}$
}

\begin{abstract}
The structural behavior of precast concrete segmental bridges largely depends on the behavior of the joints between segments. The current practice of precast concrete segmental bridges is to use small keys that are usually unreinforced, normally dry, and distributed over the height of the web and the flange of concrete segments. In this study, a numerical analysis model was established based on finite-element code to investigate structural behavior of keyed dry joints under direct shear. The concrete damage plasticity model along with the pseudodamping scheme were incorporated to analyze the system for microcracks and to stabilize the solution, respectively. The numerical model was calibrated by full-scale experimental results described in the literature. It was found that the predicted ultimate load, cracking evolution history, and final crack pattern agreed reasonably well with experimental results. The validated numerical model was then used for parametric study on factors affecting shear behavior of keyed dry joints, in this case confining pressure. The authors found that shear capacity predicted by the AASHTO code equation diverges from that predicted by numerical analysis at high confining pressure, because the contribution of friction in the total shear capacity decreased with an increase in confining pressure. Hence, the authors recommend reducing the friction coefficient used in the AASHTO code equation when high confining pressure is applied. Moreover, the propagation of inclined crack was arrested at high confining pressure owing to the fact that the fracture propagation direction is governed by the criterion of the maximum energy release rate. DOI: 10.1061/ (ASCE)BE.1943-5592.0000669. This work is made available under the terms of the Creative Commons Attribution 4.0 International license, http://creativecommons.org/licenses/by/4.0/.
\end{abstract}

Author keywords: Concrete bridges; Failure modes; FEM; Joints; Precast concrete; Shear; Shear failures; Shear strength.

\section{Introduction}

Precast concrete segmental box girder bridges externally prestressed have become more and more popular in construction resulting from the demand for economical and safe design; fast, versatile, and practical construction; and excellent serviceability of concrete bridges (Poston and Wouter 1998). The overall behavior of precast concrete segmental bridges largely depends on the joints between segments, which represent locations of discontinuity along a bridge span (Issa and Abdalla 2007). Compression and shear forces across bridge sections are transmitted through these joints (Zhou et al. 2005). Individual precast segments connected by such keyed joints are then externally prestressed forming the bridge superstructure. The current practice is to use multiple castellated small keys that are usually unreinforced in the key zone and distributed over the height of the web and flanges, to provide an improved interlocking performance.

The joints can be constructed and erected either using an epoxy layer between segments or in a dry condition. It has been concluded based on experimental results that the most significant parameters

${ }^{1} \mathrm{Ph} . \mathrm{D}$. Student in Civil Engineering, School of Engineering and Design, Brunel Univ., Uxbridge, Middlesex UB8 3PH, U.K. E-mail: Rabee .Shamass@brunel.ac.uk

${ }^{2}$ Senior Lecturer in Civil Engineering Design, School of Engineering and Design, Brunel Univ., Uxbridge, Middlesex UB8 3PH, U.K. (corresponding author). E-mail: Xiangming.Zhou@brunel.ac.uk

${ }^{3}$ Senior Lecturer in Computational Mechanics, School of Engineering and Design, Brunel Univ., Uxbridge, Middlesex UB8 3PH, U.K. E-mail: Giulio.Alfano@brunel.ac.uk

Note. This manuscript was submitted on January 24, 2014; approved on June 24, 2014; published online on August 6, 2014. Discussion period open until January 6, 2015; separate discussions must be submitted for individual papers. This paper is part of the Journal of Bridge Engineering, (c) ASCE, ISSN 1084-0702/04014084(12)/\$25.00. that affect the shear behavior of the keyed joints are the prestress value, thickness of epoxy, shape of the key, surface preparation, concrete strength, contact area of the joint, and friction coefficient between concrete-to-concrete surfaces (Buyukozturk et al. 1990). Epoxied joints are regarded as able to perform better in terms of durability and ultimate shear capacity (Koseki and Breen 1983). However, it has been found that epoxied joints fail in a brittle manner, which is not desirable in structural design. Besides, epoxy has to be put in a construction site, and the weather condition could become a dominant factor in making the epoxy's quality difficult to be controlled. It also takes time for epoxy to harden, which increases the construction period. Turmo et al. (2006b) pointed out that, when possible, the use of epoxied joints should be avoided because it redounds in time savings. Therefore, in modern precast concrete segmental bridge construction, dry joints are used more frequently.

Though concrete segmental bridges with dry joints may be susceptible to durability problems, this practice seems to be more and more popular owing to its simplicity in construction. However, the behavior of dry joints has not been understood well. Experimental results from various studies all indicated that the failure model of the shear keys was fracture of concrete along the joint with shearing off the keys (Buyukozturk et al. 1990; Zhou et al. 2005; Turmo et al. 2006b). Shear strength and stiffness of keyed dry joints increased with confining stress, i.e., prestress applied on the joint holding the male and female parts together. Most researchers accept that the shear strength of keyed dry joints is the work of two different mechanisms (Turmo et al. 2006a). The first mechanism depends on the friction resistance between the flat surfaces, which attempt to slide against each other. This resistance is proportional to the actuating compression load, i.e., the confining pressure. The second mechanism represents the support effect of the castellated shear keys, which behave like small plain concrete corbels when they are in contact. If compression stresses exist, the keys turn out to be small 
prestressed concrete corbels and the ultimate shear capacity of the keyed joint increases as compression stresses increase. Though the shear flow mechanisms across dry joints are qualitatively well known, there is no consensus regarding their quantification.

Kaneko et al. (1993a) developed a simple mechanical model for the analysis and design of plain or fiber-reinforced concrete shear key joints. Their analysis used a single discrete crack model under wedging force and a smeared crack model under remote shear force. Their proposed formulation identified two main fracture mechanisms for shear-off failure of key joints: single curvilinear cracking and development of multiple diagonal cracks. Kaneko et al. (1993a) also proposed a simple design formula as a first step in developing design aids for the shear strength of shear keys, and the authors subsequently validated their fracture mechanics model (Kaneko et al. 1993b). On the other hand, Kaneko and Mihashi (1999) presented an analytical damage model that was able to predict the nonlinear strain localization along the shear key base at the cracking transition for keyed dry joints. The model was able to describe the transition phenomenon between a large single curvilinear crack ( $\mathrm{S}$ crack) and diagonal multiple cracks ( $\mathrm{M}$ crack) observed during the shear-off failure sequence of concrete shear key joints.

Though analytical models proposed by Kaneko et al. (1993a) and Kaneko and Mihashi (1999) are scientifically sound, they are not easy to adopt directly by structural engineers in daily work for designing keyed dry joints. Neither are they easy to incorporate into a full finiteelement (FE) model for analyzing structural behavior of precast concrete segmental bridges with keyed joints. More recently, Li et al. (2013) conducted an experimental study, mainly on the behavior of keyed joints in precast concrete segmental beams under shear, bending, and combined shear and bending. They deduced formulas to evaluate the ultimate strength of keyed joints under combined shear and bending; but, it should be noted that their formulas were proposed for keyed joints subject to combined shear and bending, which is not necessarily applicable to keyed joints under direct shear, even assuming bending moment equal to zero in their formulas.

On the other hand, from a practical point of view, there are several formulas that have been proposed for ultimate shear strength of unreinforced keyed dry joints, among which some are based on experimental results and some on theoretical or numerical analysis. These formulas are all conceptually very similar, conforming to the shear stress transfer mechanism mentioned previously. Fouré et al. (1993) tested assemblies of three precast segments under external prestressing. A formula was proposed but needs to be checked more extensively by comparison with other test results, and then simplified to make for practical use. Ramirez et al. (1993) theoretically deduced a formulation to evaluate the shear strength of keyed dry joints, which later was adopted by AASHTO by applying a safety factor, $\varphi_{j}=0.75$. The AASHTO formulation (AASHTO 1999) for shear strength of keyed joints is as follows:

$$
V=A_{k} \sqrt{6.792 \times 10^{-3} f_{c m}}\left(12+2.466 \sigma_{n}\right)+\mu \cdot A_{s m} \cdot \sigma_{n}
$$

where $f_{c m}=$ characteristic compressive strength of concrete (MPa); $\sigma_{n}=$ average compressive stress in concrete across the key base area (MPa); $A_{k}=$ area of the base of all keys in the failure plane; $A_{s m}$ $=$ area of contact between flat surfaces on the failure plane; and $\mu$ $=$ friction coefficient between concrete-to-concrete surfaces, which AASHTO suggests as 0.6. It is obvious that this formula separates the shear load-bearing capacity that the joint is capable of transmitting by the keys, $A_{k}$, and the flat area, $A_{s m}$, between the keys.

Based on nonlinear FE analysis results, Rombach (1997) proposed another formula to calculate the shear capacity of keyed dry joints between bridge segments

$$
V=0.14 f_{c m} A_{k}+\mu \cdot A_{s m} \cdot \sigma_{n}
$$

where $f_{c m}, A_{k}, \mu, A_{s m}$, and $\sigma_{n}$ in Eq. (2) refer to their respective counterparts in Eq. (1). It can be seen that Rombach's formula is similar to the AASHTO one, but it does not take into consideration the internal friction of a keyed joint. It has been found that the application of Eqs. (1) and (2) leads to very different values for the ultimate shear capacity of the keyed dry joints compared with experimental values, with some results that can vary by $100 \%$ (Zhou et al. 2005; Turmo et al. 2006b).

Though there are various experimental studies on shear keys reported (notably Koseki and Breen 1983; Buyukozturk et al. 1990; Zhou et al. 2005; Turmo et al. 2006b; Li et al. 2013), there are limited numerical analyses on shear behavior of keyed joints published. Rombach (1997) conducted numerical studies on keyed dry joints using ANSYS FE code and summarized the work by a shear design formula [Eq. (2)]. Turmo et al. (2006a) conducted a FEM study on the structural behavior of simply supported segmental concrete bridges with posttension and dry joints in which castellated keyed joints were analyzed (using a flat-joint model to avoid very fine mesh needed for keys in a full FE model, to save computing cost). The joint was modeled with interface elements with different constitutive laws depending on the geometry. Also, it should be noted that the flatjoint model proposed by Turmo et al. (2006a) was a macromodel for keyed joints, mainly aimed at reducing computation cost for analysis of concrete segmental bridges with keyed joints between segments. It is not possible to predict the stress, strain, and crack evolution in keys in the joint by this model, as the keys are not modeled geometrically. The model was proposed purely for the sake of structural analysis of precast segmental concrete bridges, not for the keyed joints themselves. Accordingly, it cannot be counted as a numerical model for keyed dry joints.

For this purpose, a FE micromodel that falls within the scope of this research is needed. Kim et al. (2007) presented a numerical study on the flat joints between precast, posttensioned concrete segments in which the authors used modeling techniques very similar to those adopted by Turmo et al. (2006a). Turmo et al. (2012) presented a joint model for studying shear transfer between match-cast keyed dry joints between concrete segments. In their model, interface elements were used to reproduce the nonlinear behavior of the joint, and parameters deduced from various tests were used to define constitutive law of those interface elements for the joint. Alcalde et al. (2013) developed a FE model of four different types of joints, with a number of keys varying between one and seven, to analyze the fracture behavior of keyed dry joints under shear, focusing on the influence of the number of keys on the joint capacity and its average shear stress. The results showed that the average shear stress transferred across joints decreased with the number of keys, which is consistent with the experimental findings of Zhou et al. (2005).

There are very limited numerical studies published on the structural behavior of keyed joints between concrete segments. Thus, a numerical study was conducted by the authors based on ABAQUS 6.11-1 FE code to simulate the behavior of male-female matching single-keyed dry joints under direct shear until failure. Ultimate load capacity in shear and evolution of deformation, stress, and crack in keyed dry joints were obtained through numerical analyses and calibrated by full-scale experimental results presented elsewhere (Buyukozturk et al. 1990; Zhou et al. 2005). The numerical model then was used for parametric studies on structural behavior of keyed dry joints. Some interesting findings are presented in this paper, including a recommendation for the modification of AASHTO's formula [Eq. (1)] for shear capacity of keyed dry joints. 


\section{Numerical Study}

\section{Concrete Damage Plasticity Model}

ABAQUS code provides tools for simulating damage in concrete using one of the crack models for RC, namely, smeared crack concrete model, concrete damage plasticity (CDP) model, and brittle crack model. The CDP model was chosen in the current study for simulating concrete. It allows the definition of inelastic behavior of concrete in compression and tension stiffening in tension, including damage characteristics in both tension and compression. The CDP model can be used in applications in which concrete is subject to static and cyclic loading.

\section{Initial Parameters}

The general CDP model parameters were chosen as follows (Kmiecik and Kamiński 2011): dilation angle, flow potential eccentricity, and viscosity parameter were assigned equal to $36^{\circ}, 0.1$, and 0 , respectively; the ratio of the strength in the biaxial state to the strength in the uniaxial state, $\sigma_{b 0} / \sigma_{c 0}=1.16$; and the ratio of the second stress invariant on the tensile meridian, $K_{c}=0.666$.

\section{Stress-Strain Curve of Concrete under Uniaxial Compression}

As mentioned previously, the CDP model was selected for simulating concrete cracking and crack propagation. To use this approach, stress-strain relationships for concrete in compression and postfailure stress-strain relationship in tension are required. In this study, the complete $\sigma_{c}-\varepsilon_{c}$ curve proposed by Eurocode 2 [British Standards Institution (BSI) 2004] was adopted for concrete under compression, which suggests the following expression:

$$
\sigma_{c}=\left[\frac{k \eta-\eta^{2}}{1+(k-2) \eta}\right] f_{c m}
$$

where

$$
\begin{gathered}
\eta=\frac{\varepsilon_{c}}{\varepsilon_{c 1}} \\
k=1.05 E_{c m} \frac{\varepsilon_{c 1}}{f_{c m}} \\
\varepsilon_{c 1}(\% \mathrm{o})=0.7\left(f_{c m}\right)^{0.31} \leq 2.8 \\
E_{c m}=22\left(0.1 f_{c m}\right)^{0.3}
\end{gathered}
$$

where $E_{c m}=$ elastic modulus (GPa) of concrete; and $f_{c m}=$ ultimate compressive strength of concrete. Fig. 1 shows the complete compressive stress-strain curve of concrete with the ultimate compressive stress $f_{c m}(\mathrm{MPa})$, strain at peak stress $\varepsilon_{c 1}$, and ultimate strain $\varepsilon_{c u 1}$, which is taken as 0.0035 by Eurocode 2. A linear stress-strain relationship, which obeys Hooke's law, was assumed up to $40 \%$ of ultimate compressive strength in the ascending branch.

Inelastic strains $\widetilde{\varepsilon_{c}^{\text {in }}}$ corresponding to compressive stresses $\sigma_{c}$ were used in the CDP model. To obtain them, one has to substitute the total strain from elastic strain $\varepsilon_{o c}^{e l}$, which corresponds to undamaged material as follows:

$$
\begin{gathered}
\widetilde{\varepsilon_{c}^{i n}}=\varepsilon_{c}-\varepsilon_{o c}^{e l} \\
\varepsilon_{o c}^{e l}=\frac{\sigma_{c o}}{E_{c m}}
\end{gathered}
$$

Additionally, the compressive damage parameter $d c$ needs to be defined at each inelastic strain level. It ranges from 0 , for an undamaged material, to 1 , when the material has totally lost its loadbearing capacity. The value $d c$ is obtained only for the descending branch of the stress-strain curve of concrete in compression as follows (Fig. 2):

$$
\begin{aligned}
d_{c} & =0 \quad \varepsilon_{c}<\varepsilon_{c 1} \\
d_{c} & =\frac{f_{c m}-\sigma_{c}}{f_{c m}} \quad \varepsilon_{c} \geq \varepsilon_{c 1}
\end{aligned}
$$

Therefore, the plastic strains calculated using Eq. (11) always must be positive

$$
\widetilde{\varepsilon_{c}^{p l}}=\widetilde{\varepsilon_{c}^{i n}}-\frac{d_{c}}{\left(1-d_{c}\right)} \frac{\sigma_{c o}}{E_{c m}}
$$

\section{Postfailure Stress-Strain Relationship in Tension (Tension Stiffening)}

Tensile strength of concrete was taken as $10 \%$ of its compressive strength. Tension stiffening refers to the phenomenon that concrete can carry tension even after cracking, though tensile strength gradually decreases with increasing tensile strain. In this study, a linear

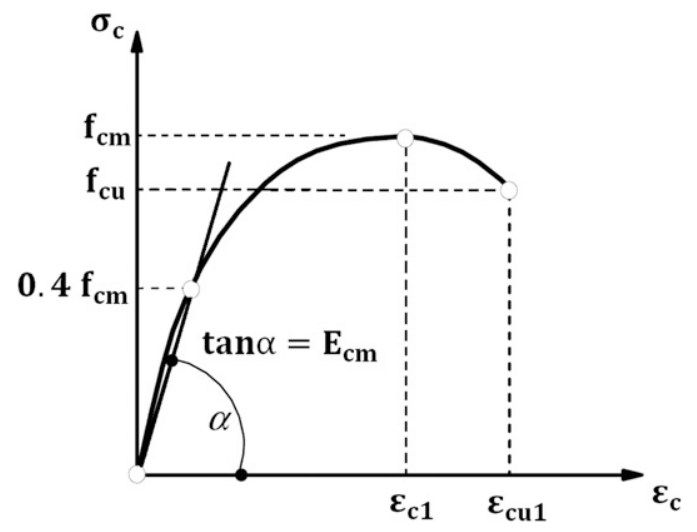

Fig. 1. Stress-strain diagram of concrete in compression according to Eurocode 2

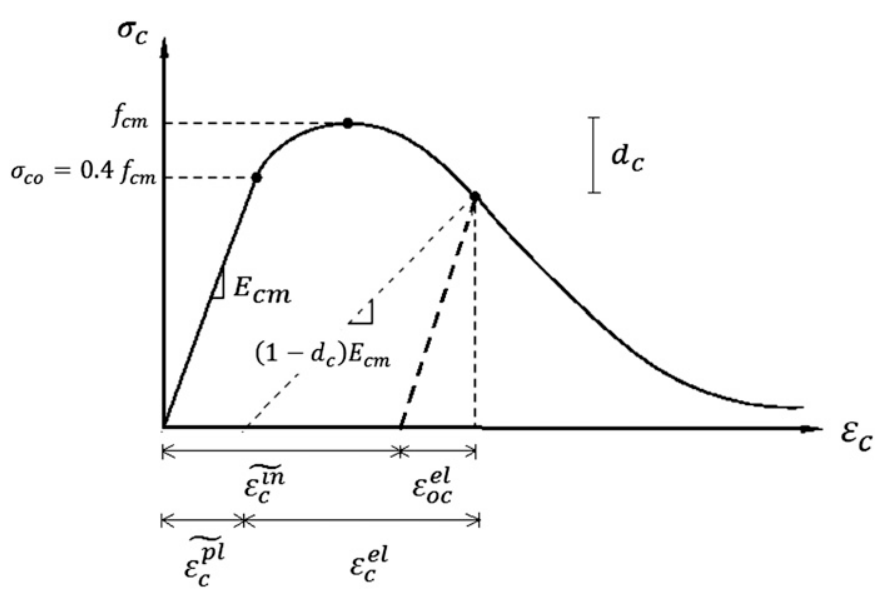

Fig. 2. CDP model in compression 
stress-strain relation (Fig. 3) was adopted for concrete in tension. It assumed that the strain softening after the failure point reduces the stress linearly to zero at a total strain of approximately 10 times the strain at tensile cracking, $\varepsilon_{c r}(A B A Q U S)$. Cracking strains $\widetilde{\varepsilon_{t}^{c k}}$ corresponding to tension stresses, $\sigma_{t}$, were used in the CDP model (Fig. 4). To obtain them, one has to subtract the elastic strain, $\varepsilon_{o t}^{e l}$, from the total tensile strain, $\varepsilon_{t}$, as follows:

$$
\begin{gathered}
\widetilde{\varepsilon_{t}^{c k}}=\varepsilon_{t}-\varepsilon_{o t}^{e l} \\
\varepsilon_{o t}^{e l}=\frac{\sigma_{t}}{E_{c m}}
\end{gathered}
$$

Similar to the case of compression, the tensile damage parameter $d t$ needs to be defined at each cracking strain. The $d t$ value is valid only at the descending branch of the stress-strain curve of concrete in tension as follows (Fig. 4):

$$
\begin{aligned}
d_{t} & =0 \quad \varepsilon_{t}<\varepsilon_{c r} \\
d_{t} & =\frac{f_{t}-\sigma_{t}}{f_{t}} \quad \varepsilon_{t} \geq \varepsilon_{c r} \\
\varepsilon_{c r} & =\frac{f_{t}}{E_{c m}}
\end{aligned}
$$

The plastic strain is defined from the following equation:

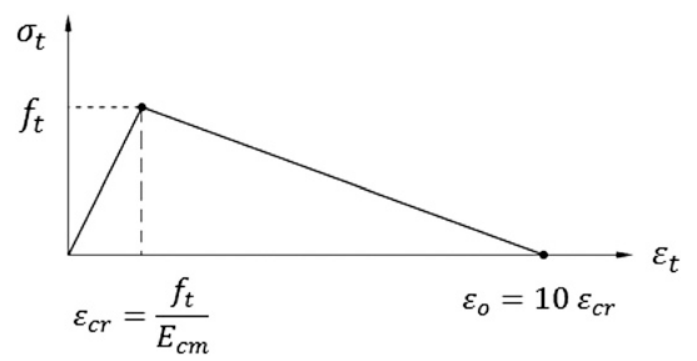

Fig. 3. Tensile $\sigma-\varepsilon$ curve for concrete: linear representation

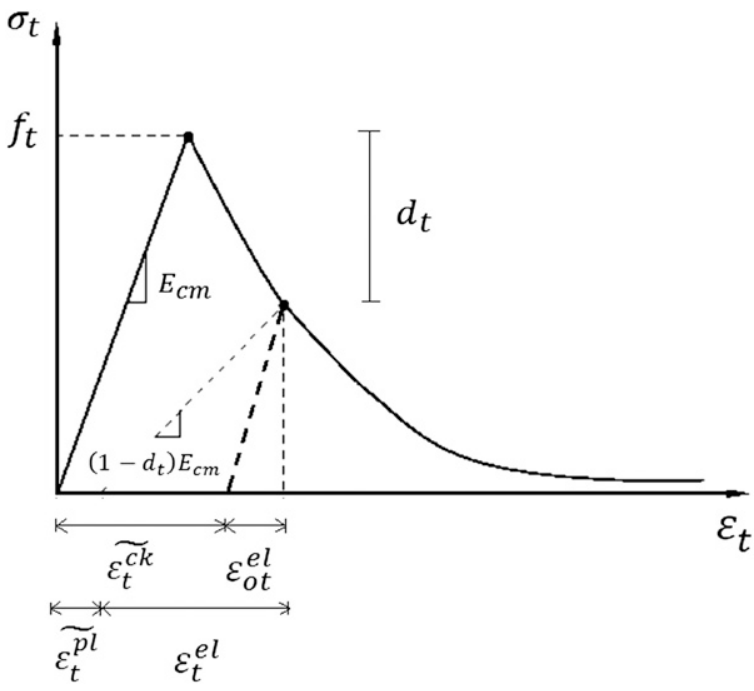

Fig. 4. CDP model in tension

$$
\widetilde{\varepsilon_{t}^{p l}}=\widetilde{\varepsilon_{t}^{c k}}-\frac{d_{t}}{\left(1-d_{t}\right)} \frac{\sigma_{t}}{E_{c m}}
$$

\section{Crack Detection in Numerical Analysis}

The CDP model does not support the concept of cracks developing at the material integration point. However, in this study, it was assumed that cracking occurred at the point when the maximum principal total strain exceeded the value of the strain, $\varepsilon_{o}=10 \varepsilon_{c r}$ (Fig. 3). Under such high strain, a concrete element totally loses its resistance to tension.

\section{Material Properties for Reinforcement Bar}

Though it has been found that the stress in the reinforcement bar was far lower than its yielding strength throughout the loading until the shear-off failure of concrete keys, without losing generality, in this study, a linear elastic and fully plastic bilinear stress-strain material model was used for reinforcement bar in tension and compression. The yield strength $f_{y}$, elastic modulus $E_{s}$, and Poisson's ratio $\nu$ of reinforcement bar were taken as $400 \mathrm{MPa}, 210 \mathrm{GPa}$, and 0.33 , respectively.

\section{Numerical Simulation}

In this study, the single-keyed dry joints tested elsewhere by Zhou et al. (2005) and by Buyukozturk et al. (1990) were analyzed using FE code $A B A Q U S$, based on the model parameters discussed previously. In Zhou's specimens, the overall dimensions of the single-keyed dry joints were $500 \times 620 \times 250 \mathrm{~mm}^{3}$ with $250 \mathrm{~mm}$ as the thickness of the joint including a male part and a female part (Fig. 5). The castellated joint had a $100 \times 250 \mathrm{~mm}^{2}$ base area and a $50 \times 250 \mathrm{~mm}^{2}$ top area with a $50-\mathrm{mm}$ depth. The most critical area in which cracking happens is the castellated keyed area, where a finer mesh with nominal element size of approximately $5 \mathrm{~mm}$ was used, compared with a coarser mesh, with the nominal element size of approximately $15 \mathrm{~mm}$, that was used for the rest of the model (Fig. 6). Four-node bilinear plane stress quadrilateral elements (CPS4) were used for modeling the key assembly. The plane stress thickness was taken as $250 \mathrm{~mm}$. There were, in total, 2,255 elements for a typical single-keyed dry joint assembly. A full integration algorithm was used in numerical analyses. For those keyed joints tested by Zhou et al. (2005), the specimen identifier was represented as $M i-D-K m-n$, where $M$ represented monotonic loading and the numeral following $M$ (in this case $i$ ) indicated the confining stress in megapascals, $D$ was identified as dry joint, $K$ indicated keyed joint, and $m$ was the key number. Lastly, $n$ represented the test number under the same testing condition.

In the experiment reported by Buyukozturk et al. (1990), the overall dimensions of the single-keyed dry joints were $533.4 \times 251$ $\times 76.2 \mathrm{~mm}^{3}\left(21 \times 10 \times 3\right.$ in. $\left.^{3}\right)$ with $76.2 \mathrm{~mm}$ ( 3 in. $)$ as the thickness of the joint including a male part and a female part. The castellated joint had a $76.2 \times 98.425 \mathrm{~mm}^{2}\left(3 \times 3.875 \mathrm{in}^{2}\right)$ base area and a $76.2 \times 66.675 \mathrm{~mm}^{2}\left(3 \times 2.625\right.$ in. $\left.^{2}\right)$ top area, with a $31.75-\mathrm{mm}$ (1.25-in.) depth (Fig. 7). Again, the most critical area is the castellated keyed area, where a finer mesh with nominal element size of approximately $3.5 \mathrm{~mm}$ was used, compared with a coarser mesh with the nominal element size of approximately $7-12 \mathrm{~mm}$ that was used for the rest of the model (Fig. 6). Similarly, four-node bilinear plane stress quadrilateral elements (CPS4) with full integration algorithm were used, and the plane stress thickness was taken as $76.2 \mathrm{~mm}$. There were, in total, 3,965 elements for a typical single-keyed dry joint assembly. In all cases, first-order truss elements were used for modeling the reinforcement bars embedded in the keyed joints. 


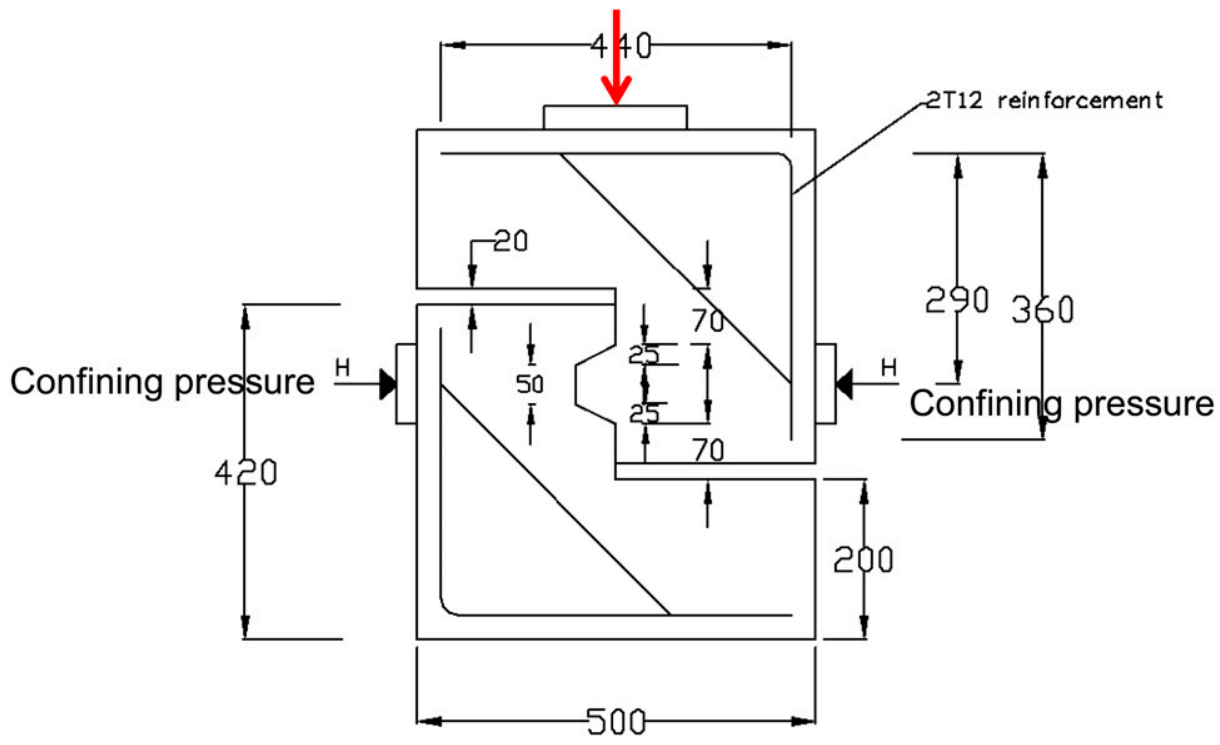

Fig. 5. Dimensions of the single-keyed joints tested by Zhou et al. (2005)

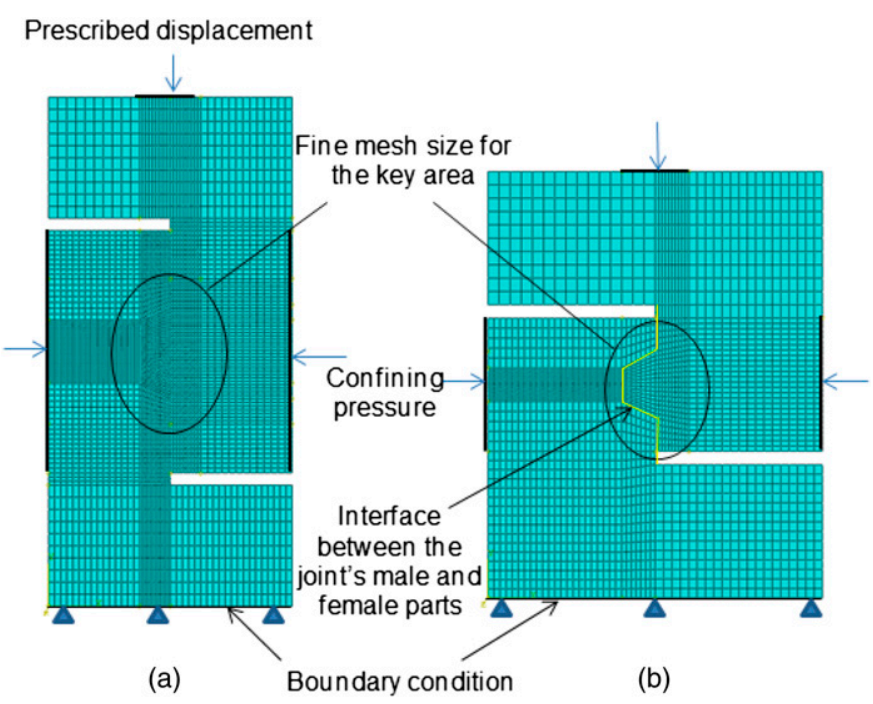

Fig. 6. FE mesh, boundary conditions, loadings, and contact relationship for (a) specimens from Buyukozturk et al. (1990); (b) specimens from Zhou et al. (2005)

\section{Contact Relationship}

The node-to-surface contact discretization provided in $A B A Q U S$ was adopted to formulate the contact simulation for both models of Zhou et al. (2005) and Buyukozturk et al. (1990). In terms of tracking approach for simulating the relative motion of two interacting surfaces in mechanical contact simulations, the small sliding analysis procedure was used in the analysis $(A B A Q U S)$. Normally, in a node-to-surface contact pair, the contact surface associated with the key part that sits on the ground (i.e., lower part) was taken as the main surface and the other surface of the contact associated with upper key part was taken as a subordinate surface. The friction coefficient for the contacting concrete surfaces in the keyed joints was derived from experimental results of flat joint tests conducted by Zhou et al. (2005) and by Buyukozturk et al. (1990). Based on their results, values of 0.72 and 0.67 were taken for the cases of Zhou's and Buyukozturk's experiments, respectively.

\section{Simulation of Reinforcement Bars Embedded in Concrete}

In this study, a technique was used to set embedded nodes at desired locations with the constraints on translational degrees of freedom on the embedded element by the host element. The reinforcement bars were modeled as the embedded region in concrete using constraints in the interaction model and designating concrete as the host region. By doing so, the rebar elements could have only a translational degree of freedom equal to that of the host elements surrounding them (Garg and Abolmaali 2009). The bar sizes used to model the reinforcements in Zhou's and Buyukozturk's specimens were $2 \Phi 12$ and $2 \Phi 10 \mathrm{~mm}$, respectively; their positions in the specimens are shown in Figs. 5 and 7, respectively.

\section{Specification of Support and Assignment of Applied Load}

In numerical analysis, the bottom surface, which contacted the ground, of the keyed joint specimen was restrained against all translational degrees of freedom. On the other hand, in all experiments conducted by Zhou et al. (2005) and Buyukozturk et al. (1990), displacement-controlled loading was applied on the top of the joint. Numerically, this was simulated by creating a boundary condition moving vertically downward, with a prescribed displacement rate as adopted in the experiments done by Zhou et al. (2005) and Buyukozturk et al. (1990), respectively, and assigning it to general-static step with damping factor used for automatic stabilization. For the case of Zhou et al. (2005) specimens, the confining stress was simulated by applying constant uniform pressure on both sides of the model, covering a keyed area of $200 \times 250 \mathrm{~mm}^{2}$ and assigned to general-static step. The confining stress values were 1, 2, 3, 4, and 4.5 MPa, respectively, as per Zhou et al. (2005). Similarly, for the case of the Buyukozturk et al. (1990) specimens, the confining pressure was applied covering a keyed area of 254 $\times 76.2 \mathrm{~mm}^{2}$ and assigned to general-static step. The confining pressure values were $0.69,2.07$, and $3.45 \mathrm{MPa}$, respectively, as per Buyukozturk et al. (1990). 


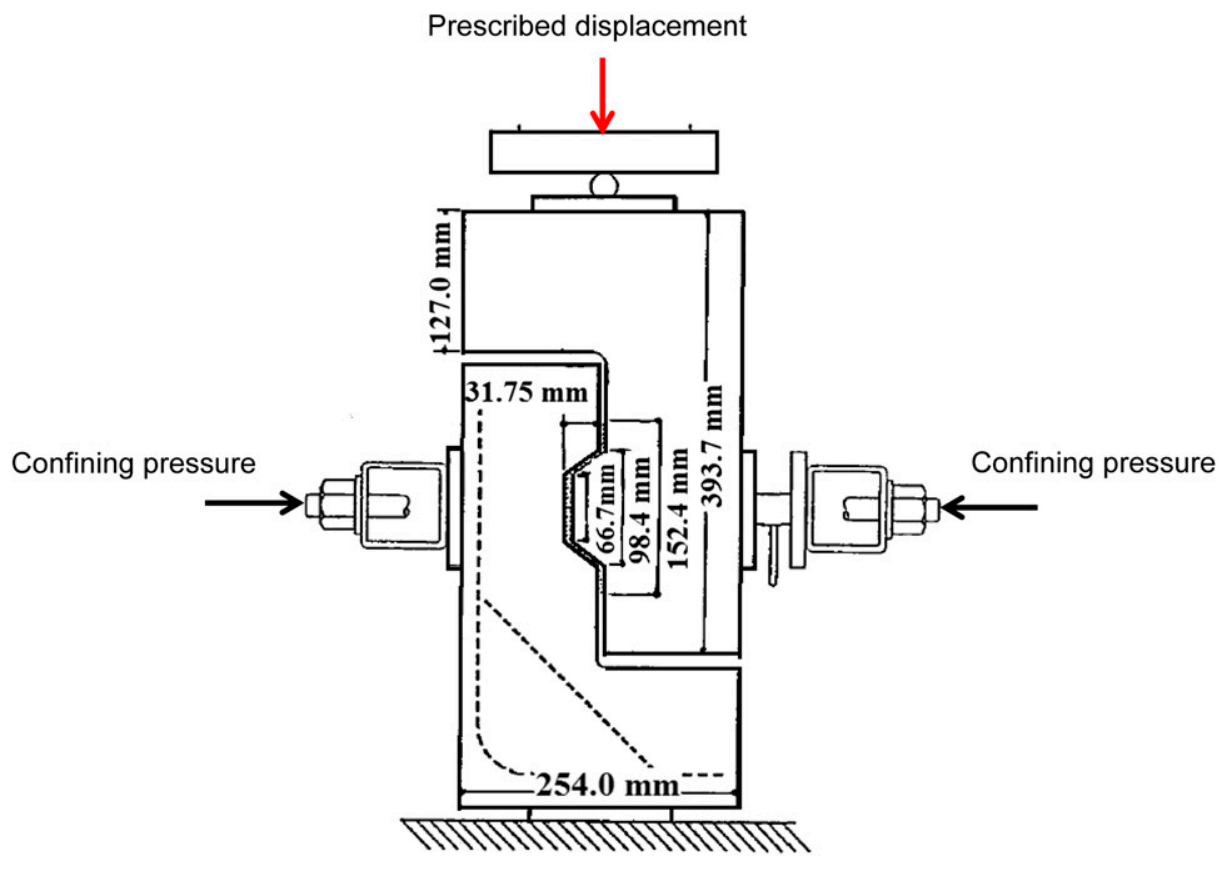

Fig. 7. Dimensions of the single-keyed joints tested by Buyukozturk et al. (1990) (adapted from Buyukozturk et al. 1990)

Table 1. Ultimate Shear Strength of Single-Keyed Dry Joints: Experimental versus Numerical

\begin{tabular}{|c|c|c|c|c|}
\hline Test name & $f_{c m}(\mathrm{MPa})$ & $\begin{array}{l}\text { Experimental ultimate } \\
\text { strength }(\mathrm{kN})\end{array}$ & $\begin{array}{l}\text { Numerical ultimate } \\
\text { strength }(\mathrm{kN})\end{array}$ & $V_{u(\text { Numerical })} / V_{u(\text { Experimental })}$ \\
\hline M1-D-K1-1 & 38.7 & 193 & 180.8 & 0.94 \\
\hline M1-D-K1-2 & 50.0 & 211 & 219.1 & 1.04 \\
\hline M2-D-K1-1 & 56.2 & 335 & 294 & 0.88 \\
\hline M2-D-K1-2 & 59.6 & 337 & 314 & 0.93 \\
\hline M3-D-K1-1 & 80.1 & 448 & 429 & 0.96 \\
\hline M3-D-K1-2 & 48.8 & 360 & 324 & 0.90 \\
\hline M4-D-K1-1 & 37.1 & 354 & 312 & 0.88 \\
\hline M4-D-K1-2 & 36.7 & 392 & 309 & 0.79 \\
\hline M4.5-D-K1-1 & 37.7 & 375 & 332 & 0.89 \\
\hline Keyed Dry-0.69 MPa & 48.4 & 66 & 59 & 0.9 \\
\hline Keyed Dry-2.07 MPa & 47.6 & 84 & 78 & 0.93 \\
\hline Keyed Dry-3.45 MPa & 49.44 & 111 & 99 & 0.89 \\
\hline Average & & & & 0.91 \\
\hline
\end{tabular}

\section{FE Analysis Results}

\section{Load-Displacement Relationship}

The analytical values of the ultimate loads/shear strength of nine single-keyed dry joints are summarized in Table 1, along with the corresponding experimental values reported by Zhou et al. (2005) and Buyukozturk et al. (1990). The predicted ultimate shear strength for joints are all in good agreement with the corresponding experimental results. The average deviation is approximately $9 \%$. It appears that the model used in the analysis is reliable and it is generally conservative in predicting the ultimate shear strength of a single-keyed dry joint.

Figs. 8 and 9 show numerical results of the applied load versus the deflection at the top surface of the joint. There is an obvious drop in loading at ultimate strength in all the load-displacement curves obtained from numerical simulation, which is associated with shearoff failure of the key (i.e., the corbel-like key is totally sheared off the base of the male part of the joint, which represents ultimate failure of joint). Generally, the ultimate shear strength of the joint increased as confining pressure increased. Also, a higher concrete strength led to higher ultimate shear strength of the joint. After shearoff failure of the keys, residual strength was kept, which is owing to friction between cracked concrete surfaces under confinement. The residual strength of a joint largely depends on the confining pressure (Fig. 8). As confining pressure increased from 1 to $4.5 \mathrm{MPa}$, the residual strength generally increased; but, it also depends on concrete strength. M3-D-K1-1 demonstrated the highest residual strength owing to the highest concrete strength $(80.1 \mathrm{MPa})$ of the nine single-keyed dry joints tested by Zhou et al. (2005). Also apparent from Fig. 8, the initial stiffness increased with the increase of confining pressure, and the vertical deformation of the joint at peak load increased as confining pressure increased. For those single-keyed dry joints tested by Buyukozturk et al. (1990), these findings are more obvious as the concrete for making the three keyed joints was the same grade of concrete. Both ultimate shear strength 

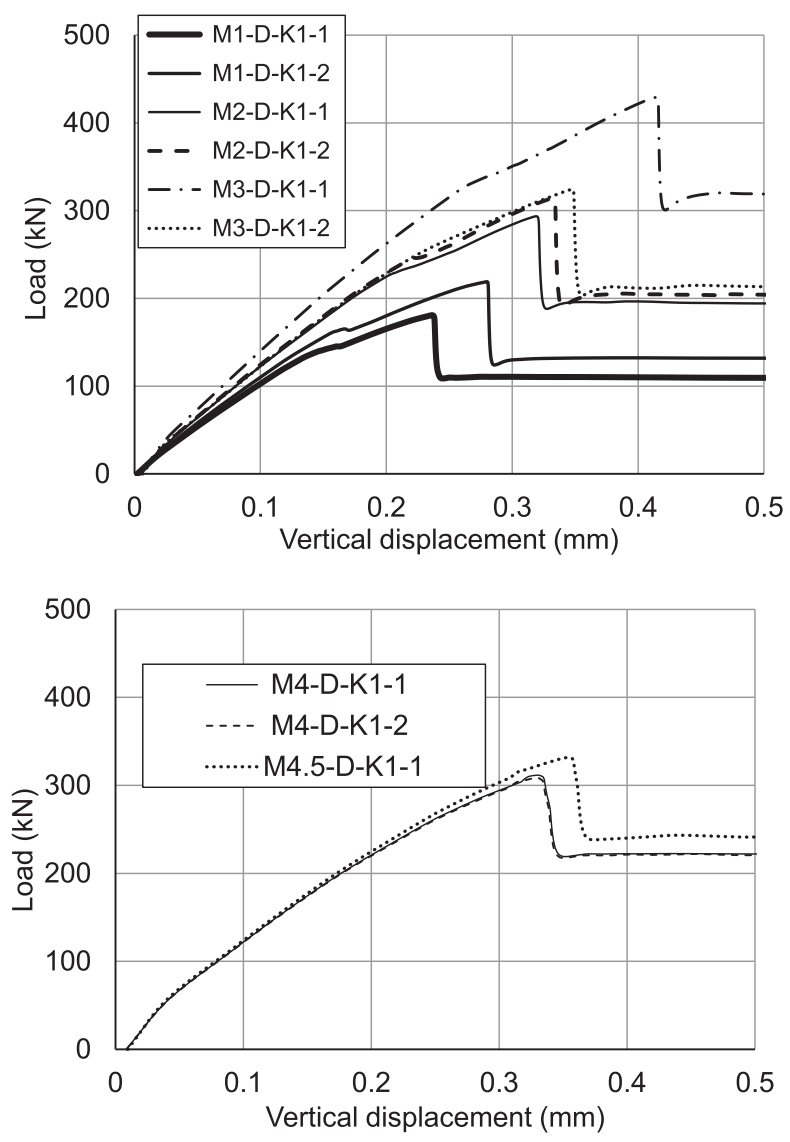

Fig. 8. Load-displacement curves from numerical analysis for keyed dry joints of Zhou et al. (2005)

and residual strength of keyed dry joint increased as confining pressure increased (Fig. 9). Again, initial stiffness and vertical deformation of the joint at peak load increased as confining pressure increased.

\section{Crack Pattern}

Figs. 10( $a$ and $b$ ) show the crack patterns for the specimen M1-DK1-2 associated with tension strains of $\varepsilon_{o}$ (Fig. 3) or higher and concrete crushing associated with compression strain 0.0035 or higher (Fig. 1) at the applied loads of 161, 165, 219, 211, and $166 \mathrm{kN}$, which correspond to the applied displacements of $0.157,0.167,0.28$, 0.281 , and $0.282 \mathrm{~mm}$, respectively. Additionally, Figs. 11(a and b) present the crack patterns and crush evolution of the specimen M3D-K1-1 at the applied loads of $328,344,429$, and $383 \mathrm{kN}$, which correspond to the applied displacements of $0.266,0.289,0.415$, and $0.416 \mathrm{~mm}$, respectively. Moreover, Figs. 12( $\mathrm{a}$ and b) show the crack patterns and crush evolution of the specimen Keyed Dry-2.07 MPa at the applied loads of $63,68,78$, and $65 \mathrm{kN}$, which correspond to the applied displacements of $0.251,0.284,0.358$, and $0.360 \mathrm{~mm}$, respectively.

From these predicted crack evolution histories, one can see that basically cracking initiates at the bottom corner of a key and propagates sideways and upward at approximately $45^{\circ}$ to the horizontal; then this crack ceases to grow. Later on, vertical cracking, which is a new crack, initiates from the bottom of the key and propagates upward vertically in the loading plane. It is this crack initiated later that causes the ultimate shear-off failure of the key from its base when it propagates to the top corner of the key. Comparing crack evolutions

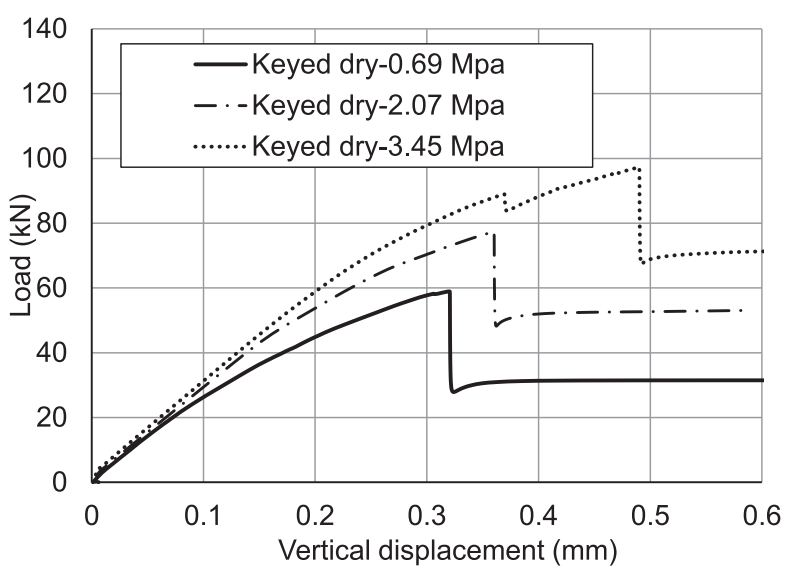

Fig. 9. Load-displacement curves from numerical analysis for keyed dry joints of Buyukozturk et al. (1990)

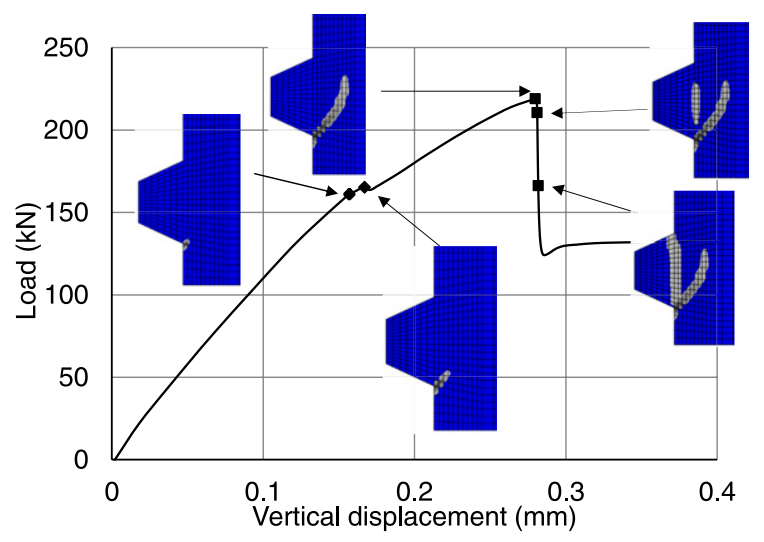

(a)

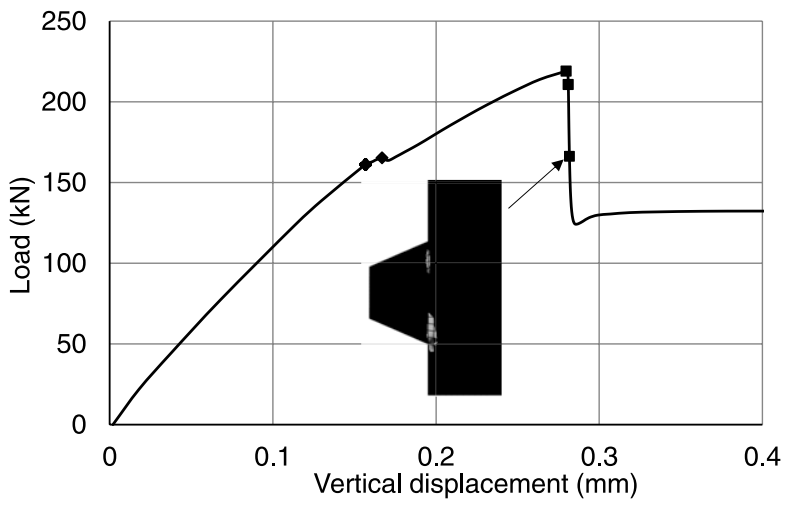

(b)

Fig. 10. (a) Crack patterns of specimen M1-D-K1-2; (b) concrete crushing evolution on the root of the key specimen M1-D-K1-2

obtained from numerical analysis to those from experiment (Figs. 13 and 14), they are highly similar, further indicating that the microscopic FE model developed in this study for keyed dry joints is reliable.

Numerous points on the FE-predicted load-displacement curve in Fig. 10(a) for the specimen M1-D-K1-2, Fig. 11(a) for the specimen M3-D-K1-1, and Fig. 12(a) for the specimen Keyed Dry-2.07 MPa were chosen to interpret crack initiation and the propagation process. All these figures obtained from numerical analyses from various specimens indicated similar crack evolution 


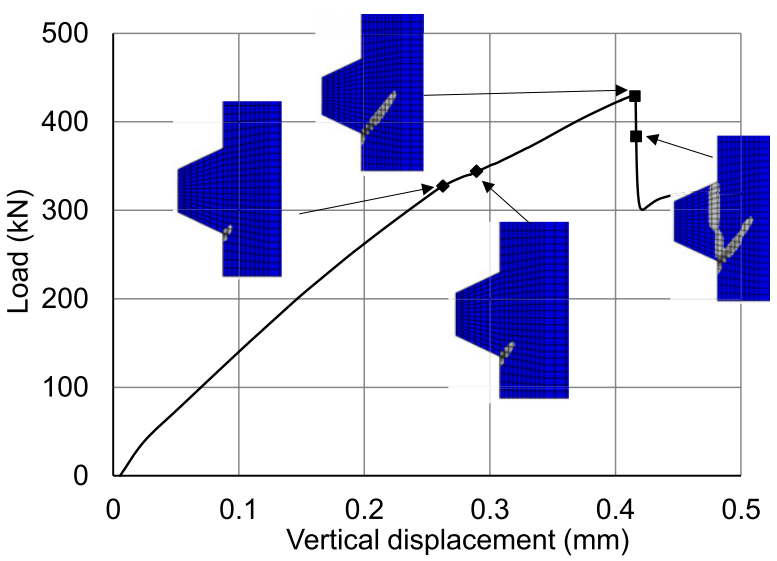

(a)

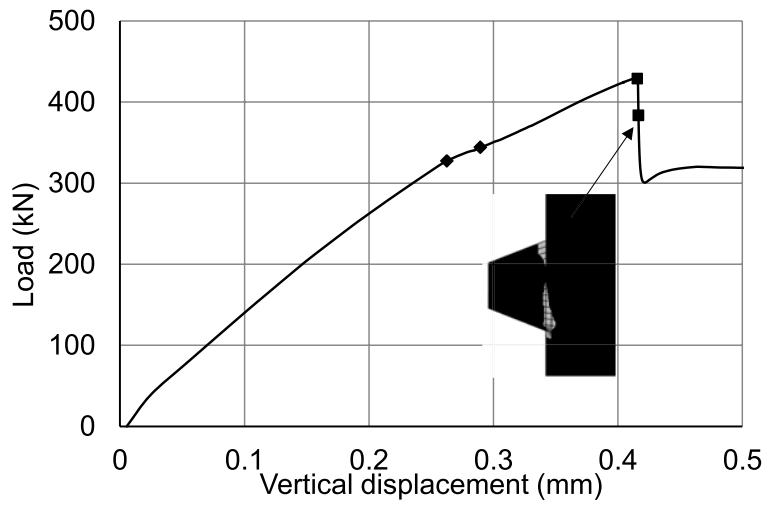

(b)

Fig. 11. (a) Crack patterns of specimen M3-D-K1-1; (b) concrete crushing evolution on the root of the key specimen M3-D-K1-1

and ultimate shear-off failure. The crack pattern obtained numerically revealed that the crack, which is called S crack, first formed at the bottom corner of the key of the male part of a joint at approximately $72-80 \%$ of the ultimate shear strength and propagated sideways and upward from the base key at almost $45^{\circ}$, which is coincident with experimental observations (Figs. 13 and 14). As the load increased until the ultimate load, a complete $S$ crack happened and short diagonal cracks started to appear along the root of the key once the load dropped beyond the ultimate load and formed a compression strut. After that, the distribution of diagonal cracks along the root key increased and formed multiple cracks. That indicates all the concrete fibers at the base key were cracked and the compression struts between multiple diagonal cracks exposed to crushing [Figs. 10(b), 11(b), and 12(b)], which coincides well with the experimental observation that there was concrete in the surface of keyed area spalling (Zhou et al. 2005).

On the other hand, the experiments revealed the formation of the diagonal multiple cracks along the root of the key, which eventually separated the key from the male part resulting in the so-called shearoff failure. The reason why numerical results showed a sudden decrease in the load-deflection curve could be because all the concrete fibers along the root of the key were cracked and crushed simultaneously, owing to the same material properties being assumed for the whole concrete volume. However, experimental observations do not show a sudden drop in load, because a direct failure plane formed along the joint surface and the load then was carried mainly through friction by aggregate interlock between cracked concrete surfaces, which is not able to be simulated by the FE model developed in this study.

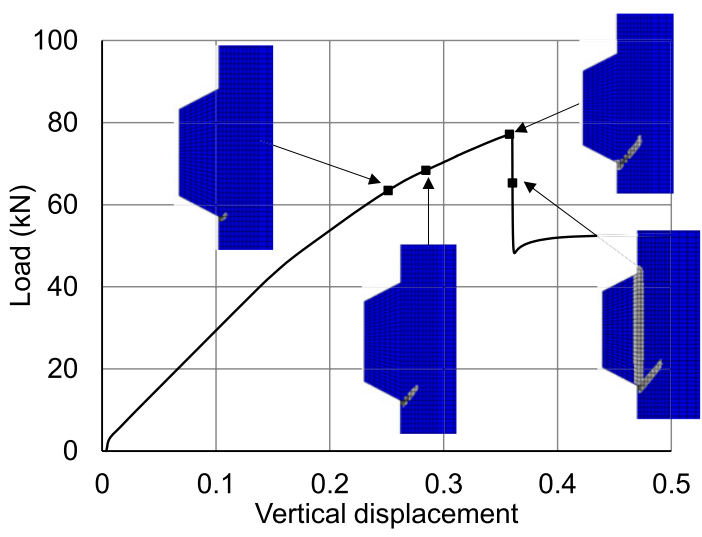

(a)

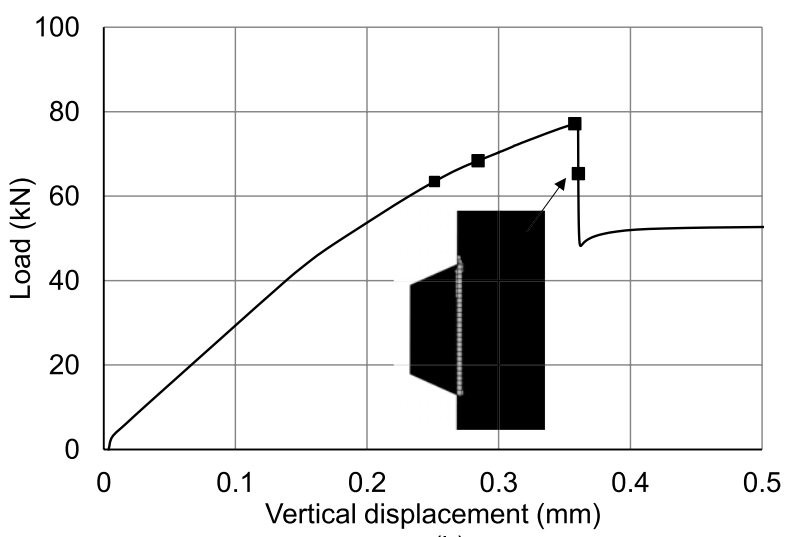

(b)

Fig. 12. (a) Crack patterns of specimen Keyed Dry-2.07 MPa; (b) concrete crushing evolution on the root of the key specimen Keyed Dry-2.07 MPa

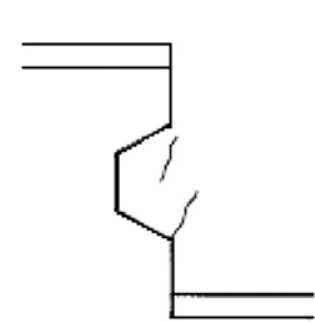

(a)

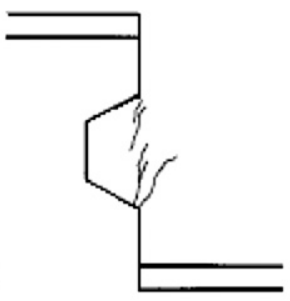

(b)

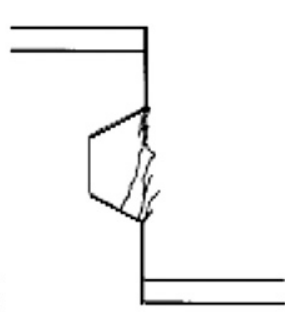

(c)
Fig. 13. Crack pattern obtained from experiment reported by Zhou et al. (2005) (reprinted from Zhou et al. 2005, with permission from the American Concrete Institute): (a) crack initiation; (b) crack propagation; (c) final crack pattern

\section{Parametric Study: Effect of Confining Pressure}

\section{Load-Displacement Relationship}

The ultimate shear strength and structural behavior of a joint is affected by concrete strength and confining pressure. Parametric study was carried out on the specimens M2-D-K1-1, M3-D-K1-1, and M3-D-K1-2, which had concrete compressive strengths equal to $56.2,80.8$, and 48.8 MPa, respectively, and were assigned different values of confining pressure ranging between 1 and $9 \mathrm{MPa}$. Restricting attention to the numerical results obtained for specimen M2-D-K1-1, applied load versus the deflection at the top surface of the specimen of the joint is shown in Fig. 15. The initial stiffness, vertical displacement at the peak load, and ultimate shear strength of 


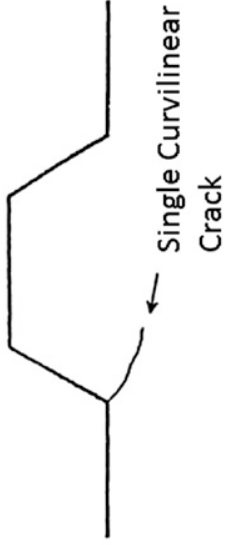

(a)

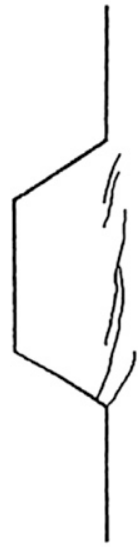

(b)

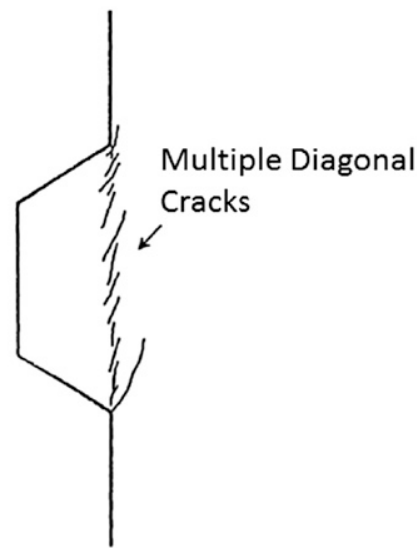

(c)
Fig. 14. Crack pattern obtained from experiment reported by Buyukozturk et al. (1990) (reprinted from Buyukozturk et al. 1990, (C) ASCE): (a) crack initiation; (b) crack propagation; (c) final crack pattern

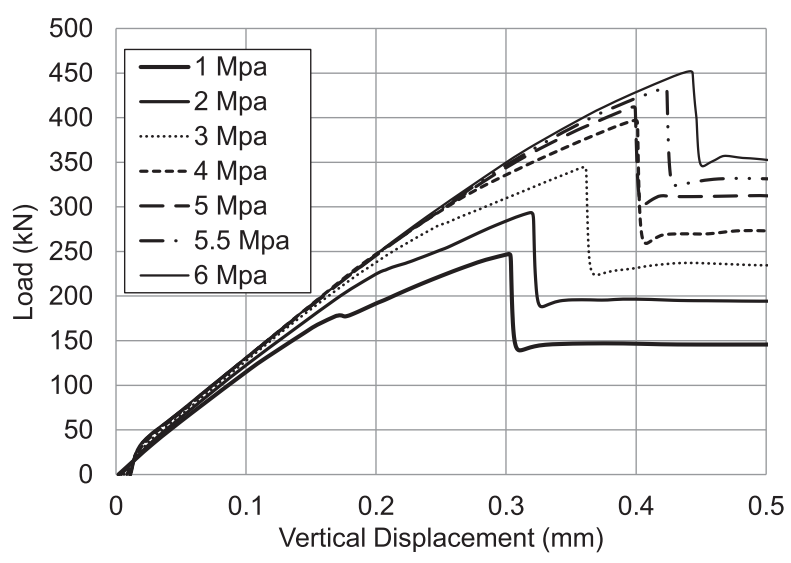

Fig. 15. Load-displacement curves for specimen M2-D-K1-1 under various values of confining pressure
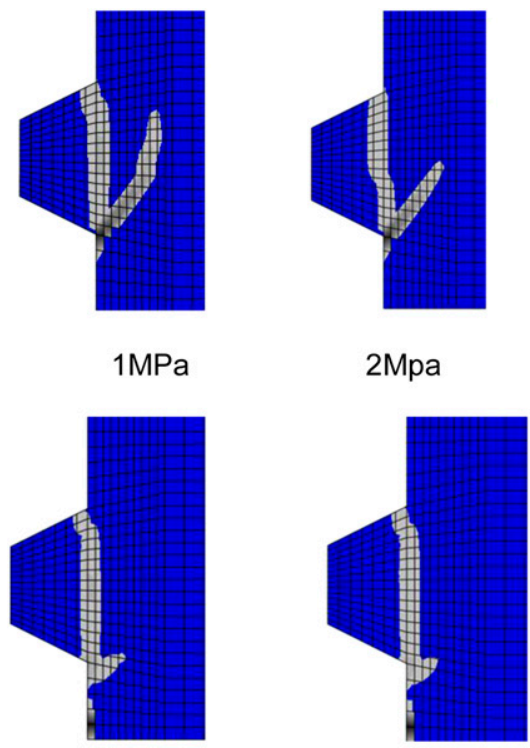

$5 \mathrm{Mpa}$ the joint increased as confining pressure increased, similar to the behavior of other prestressed concrete elements and structures. It is the confining pressure enforced by prestressing or posttensioning tendons that make the individual concrete segments form the bridge superstructure and maintain the integrity of the bridge.

\section{Crack Propagation}

Fig. 16 shows the final crack pattern of the M2-D-K1-1 single-keyed dry joint under different values of confining pressure. As the confining pressure increased, the length of the crack forming at the bottom key of the male part of the joint (S crack) decreased, and, therefore, most of the load was transferred through the bearing of the lower surface of the key. Interestingly, when the confining pressure increased to $6 \mathrm{MPa}$, this single crack disappeared. The $\mathrm{S}$ crack can be explained by the fact that this crack propagated sideways into a low stress zone in the material and thus released energy (Bazant and Pfeiffer 1986). Therefore, increasing confining pressure leads to a high compression stress zone at the entire key area, which arrests the inclined crack and induces other cracks running vertically to remain in a high stress zone, causing a large release of strain energy enforced by the applied shear loading on the joint specimen.

\section{Comparison with the AASHTO Formula}

Shear capacities of the keyed dry joint obtained from numerical analyses conducted on M2-D-K1-1, M3-D-K1-1, and M3-D-K1-2 in this study with counterparts estimated using the AASHTO formula [Eq. (1)], under different values of confining pressure, are illustrated in Figs. 17-19. The results are almost identical under low values of confining stress; however, the numerical analysis results and AASHTO results start to diverge under high values of confining pressure. For instance, the numerical results for M2-D-K1-1 and M3-D-K1-2 diverged from AASHTO predictions after the confining pressure became greater than $4 \mathrm{MPa}$, as shown in Figs. 17 and 19.

To explain the differences between the shear capacity of a single-keyed dry joint predicted by the numerical analysis established in this paper and the AASHTO formulation, the numerical model was run for frictionless contact in the malefemale joint while a zero friction coefficient was assigned to the AASHTO formula. The resulting shear capacities of various joint

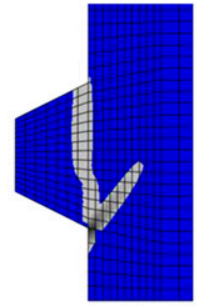

$3 \mathrm{Mpa}$

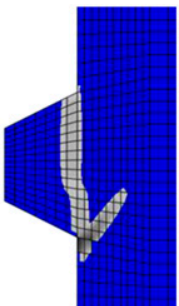

$4 \mathrm{Mpa}$

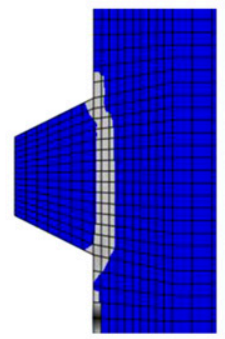

$6 \mathrm{Mpa}$

Fig. 16. Final crack pattern of specimen M2-D-K1-1 under various values of confining pressure 


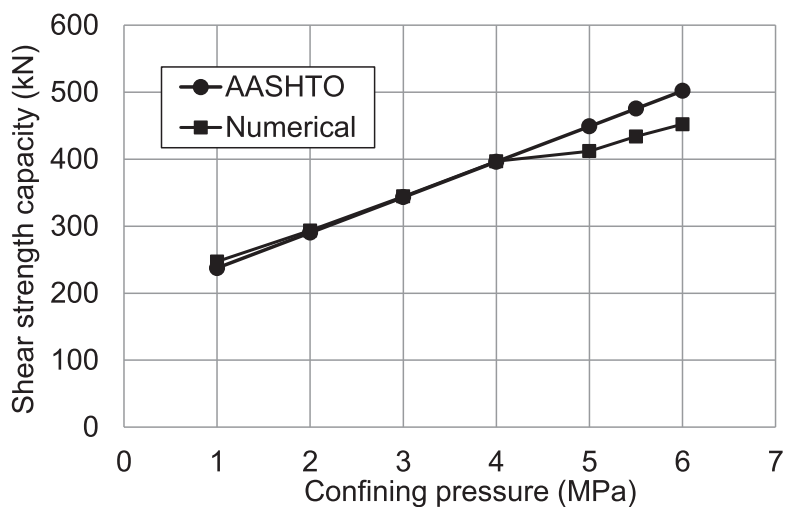

Fig. 17. Ultimate shear strength of specimen M2-D-K1-1 from numerical analysis and the AASHTO formula under various values of confining pressure

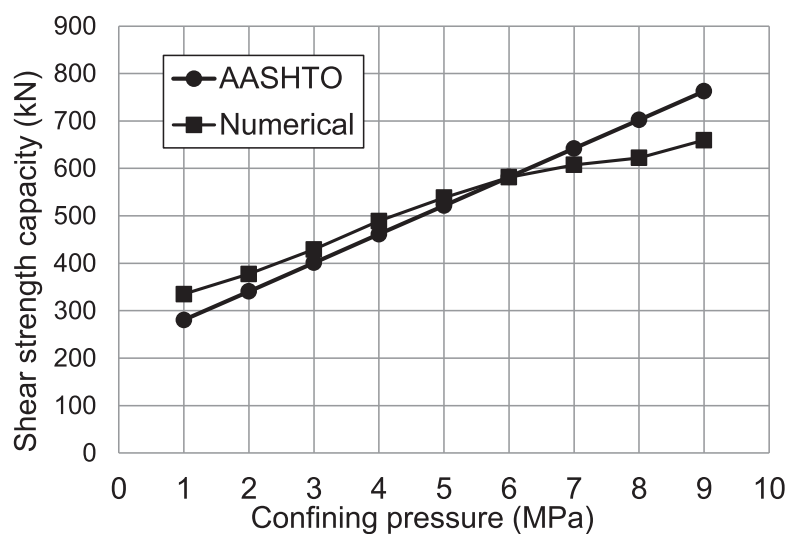

Fig. 18. Ultimate shear strength of specimen M3-D-K1-1 from numerical analysis and the AASHTO formula under various values of confining pressure

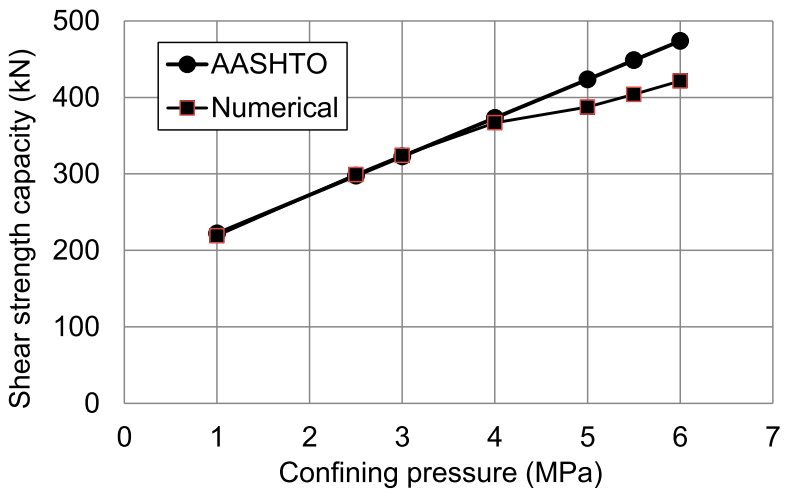

Fig. 19. Ultimate shear strength of specimen M3-D-K1-2 from numerical analysis and the AASHTO formula under various values of confining pressure

specimens under different values of confining pressure are presented in Tables 2 and 3, respectively. The numerical results indicate a decrease in friction contribution in the overall shear capacity of a keyed dry joint with an increase in the confining pressure. However, the AASHTO formulation demonstrates a different trend; it shows an increase in friction contribution with an increase in the confining pressure.

Friction between two contacting surfaces is produced when the surfaces are not perfectly smooth (Turmo et al. 2006a). In a case of solid-to-solid contact, surface roughness contributes to the relative motion resistance of the contacting surfaces. The small protuberances existing on the surfaces act against the relative displacement of the contact surfaces. In cases of concrete surfaces, the protuberances are cement paste debris spread on them (Tassios and Vintzeleou 1987). As confining pressure increases, a polishing effect takes place, which slowly rubs the irregularities and reduces the friction coefficient (Turmo et al. 2006a). With the increasing confining pressure, the debris on the contacting surfaces of the male and female parts of a keyed dry joint tends to be crushed into powder, which reduces roughness of the contacting surfaces and in turn decreases the friction coefficient. This polishing effect is visually inappreciable but can be observed when examining the surfaces once the malefemale keyed dry joints are disbanded after the test (Turmo et al. 2006a). The entire surface appears covered with a fine powder produced during the test (Turmo et al. 2006a). Similar findings have been reported by Tassios and Vintzeleou (1987), who concluded that the friction coefficient between two concrete surfaces decreases with an increase in confining pressure.

Thus, it is reasonable to accept that shear capacity due to surface friction of a keyed dry joint decreases with the increase in confining pressure, and one may conclude that the friction should have a decreasing contribution to the overall shear capacity of a keyed dry joint with increasing confining pressure, as the numerical analysis discovered. Consequently, the results based on the numerical model established in this paper are more reliable than the AASHTO predictions for keyed dry joints under high confining pressure. The authors suggest that a reduced friction coefficient $\mu$ should be assigned in the AASHTO formula [Eq. (1)] under high confining pressure.

\section{Crack Width}

The calculated crack width for M2-D-K1-1 is presented at ultimate shear strength under various values of confining pressure in Table 4. The crack width is identified at the bottom corner of the key of the male part of the joint, as shown in Fig. 20. The crack width was not measured directly in experiment, but it deserves a comparison of such a parameter under different values of confining stress. In numerical analyses of this research, crack width was calculated by multiplying the crack opening strain, which is equal to the strain normal to the crack direction after the complete stress release with the characteristic element length or crack bandwidth (Kaneko 1992). The characteristic element length in $A B A Q U S$ is a typical length of a line across an element for a first-order element (Kaneko 1992). As evident from Table 4, the crack width decreased as the confining pressure increased and became negligible under high values of confining stress, which is consistent with crack evolution observed experimentally. As previously stated, the $\mathrm{S}$ crack disappeared under high values of confining pressure, indicating that crack width may decrease to zero under certain high values of confining pressure.

\section{Conclusion}

This research aimed to better understand behavior of single-keyed dry joints in precast concrete segmental bridges by establishing and validating a FE model for keyed dry joints under direct shear. The numerical approach used to simulate the nonlinear behavior of concrete in this paper was the ABAQUS CDP model. The numerical 
Table 2. Friction Contribution from Numerical Analysis and the AASHTO Code (Specimen M3-D-K1-1)

\begin{tabular}{|c|c|c|c|c|c|c|}
\hline \multirow{2}{*}{$\begin{array}{l}\text { Confining } \\
\text { pressure (MPa) }\end{array}$} & \multicolumn{3}{|c|}{ Numerical analysis $(\mathrm{kN})$} & \multicolumn{3}{|c|}{ AASHTO formulation $(\mathrm{kN})$} \\
\hline & With friction contact & Frictionless contact & Friction effect (\%) & With friction contact & Frictionless contact & Friction effect (\%) \\
\hline 1 & 335 & 196 & 41.39 & 281 & 266 & 5.35 \\
\hline 3 & 429 & 396 & 7.77 & 401 & 356 & 11.2 \\
\hline 4 & 489 & 473 & 3.18 & 461 & 401 & 13.01 \\
\hline 5 & 538 & 479 & 10.99 & 522 & 447 & 14.4 \\
\hline 8 & 622 & 602 & 3.29 & 702 & 582 & 17.09 \\
\hline 9 & 660 & 642 & 2.59 & 763 & 628 & 17.70 \\
\hline
\end{tabular}

Table 3. Friction Contribution from Numerical Analysis and the AASHTO Code (Specimen M3-D-K1-2)

\begin{tabular}{|c|c|c|c|c|c|c|}
\hline \multirow{2}{*}{$\begin{array}{l}\text { Confining } \\
\text { pressure (MPa) }\end{array}$} & \multicolumn{3}{|c|}{ Numerical analysis $(\mathrm{kN})$} & \multicolumn{3}{|c|}{ AASHTO formulation $(\mathrm{kN})$} \\
\hline & With friction contact & Frictionless contact & Friction effect $(\%)$ & With friction contact & Frictionless contact & Friction effect $(\%)$ \\
\hline 1 & 219 & 196 & 10.63 & 222 & 207 & 6.75 \\
\hline 2.5 & 299 & 279 & 6.80 & 298 & 260 & 12.60 \\
\hline 3 & 324 & 301 & 7.26 & 323 & 278 & 13.94 \\
\hline 4 & 367 & 338 & 7.93 & 373 & 313 & 16.08 \\
\hline 5 & 387 & 370 & 4.34 & 424 & 349 & 17.71 \\
\hline 5.5 & 404 & 390 & 3.49 & 449 & 366 & 18.39 \\
\hline 6 & 421 & 409 & 3.04 & 474 & 384 & 18.99 \\
\hline
\end{tabular}

Table 4. Crack Width at the Ultimate Shear Strength of Keyed Dry Joints from Numerical Analysis (Specimen M2-D-K1-1)

\begin{tabular}{lcc}
\hline & \multicolumn{2}{c}{ At the peak load } \\
\cline { 2 - 3 } Confining pressure (MPa) & Ultimate load $(\mathrm{kN})$ & Crack width $(\mathrm{mm})$ \\
\hline 1 & 247 & 0.320 \\
2 & 294 & 0.206 \\
3 & 344 & 0.178 \\
4 & 397 & 0.128 \\
5 & 412 & 0.033 \\
5.5 & 434 & 0.031 \\
6 & 452 & 0.035 \\
\hline
\end{tabular}

results were produced in the form of ultimate shear strength of keyed joint, load-deflection curves, crack evolution, and concrete crushing evolution in keyed zone for various joints. The validated numerical model then was used for parametric studies on the behavior of keyed dry joints, which were not physically tested. By comparing numerical results with experimental results published elsewhere, the following conclusions may be drawn:

- Good agreement between experimental and numerical results was obtained for all 12 dry keyed joints tested elsewhere. Crack propagation obtained from numerical simulation accords very well with that from experimental study for all the specimens. The maximum deviation in the prediction of ultimate shear strength was found to be $9 \%$, and the results validated the FE model established in this study. The FE model can be used conveniently to simulate shear behavior of multiple-keyed dry joints.

- The ultimate failure of the dry keyed joints was fracture of concrete along the root of the key with shearing off. Cracking initiated at the bottom corner of a key and propagated sideways

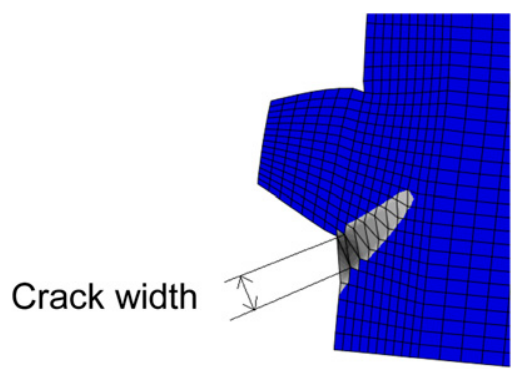

Fig. 20. Location where crack width was taken in numerical analysis

and upward at approximately $45^{\circ}$; then this crack ceased to grow. Subsequently, vertical cracking, which was a new crack, initiated from the bottom of the key and propagated upward vertically along the loading plane. It was this later crack that caused ultimate shear-off failure of the key from its base when it propagated to its top corner.

- The initial stiffness, vertical displacement at the peak load, and ultimate shear strength of a keyed dry joint increased as the confining pressure increased. On the other hand, the length of the crack that formed at the bottom key of the male part of the joint ( $S$ crack) decreased as the confining pressure increased, and, therefore, most of the load was transferred through the bearing of the lower surface of the key. At high confining stress, the $S$ crack disappeared. This phenomenon may be explained in that the entire key area experienced a high stress zone under high confining pressure and, therefore, arrested the inclined crack and instead induced another cracking mechanism, which was exposed under a higher stress zone and caused a larger release of strain energy. Moreover, the S crack width decreased as the 
confining pressure increased and became negligible under high values of confining stress.

- The AASHTO formula predicts the ultimate shear strength of keyed dry joints under low values of confining stress well when compared with numerical results. However, it overpredicts the ultimate shear strength of keyed dry joints under high confining stress. The authors suggest that a reduced friction coefficient should be assigned to AASHTO's formula for estimating shear capacity of keyed dry joints under high confining pressure.

It should be noted that the numerical model established in this study is only for simulating behavior of keyed dry joints under direct static shear caused by vertical load. In precast concrete segmental bridges, keyed dry joints may be subject to static load and/or dynamic transverse load, for which further studies are needed.

\section{Acknowledgments}

The financial support from the U.K. Engineering and Physical Sciences Research Council (EPSRC) under the grant of EP/I031952/1 is gratefully acknowledged. The first author also gratefully acknowledges the financial support provided by Damascus University for his study at Brunel University.

\section{References}

AASHTO. (1999). Guide specifications for design and construction of segmental concrete bridges, 2nd Ed., Washington, DC.

ABAQUS 6.11-1 [Computer software]. Waltham, MA, Dassault Systèmes.

Alcalde, M., Cifuentes, H., and Medina, F. (2013). "Influence of the number of keys on the shear strength of post-tensioned dry joints." Mater. Constr., 63(310), 297-307.

ANSYS [Computer software]. Canonsburg, PA, Ansys.

Bazant, Z. P., and Pfeiffer, P. A. (1986). "Shear fracture tests of concrete." Mater. Struct., 19(2), 111-121.

British Standards Institution (BSI). (2004). "Eurocode 2: Design of concrete structures. Part 1-1: General rules and rules for buildings." BS EN 1992 1-1:2004, London.

Buyukozturk, O., Bakhoum, M. M., and Beattie, S. M. (1990). "Shear behavior of joints in precast concrete segmental bridges." J. Struct. Eng., 10.1061/(ASCE)0733-9445(1990)116:12(3380), 3380-3401.

Fouré, B., Bouafia, Y., Soubret, R., and Thomas, P. (1993). "Shear test on keyed joints between precast segments." Proc., Workshop on Behaviour of External Prestressing in Structures, French Construction Association (AFPC), Saint-Rémy-lès-Chevreuse, France, 297-319.

Garg, A. K., and Abolmaali, A. (2009). "Finite-element modeling and analysis of reinforced concrete box culverts." J. Transp. Eng., 10.1061/ (ASCE)0733-947X(2009)135:3(121), 121-128.
Issa, M. A., and Abdalla, H. A. (2007). "Structural behavior of single key joints in precast concrete segmental bridges." J. Bridge Eng., 10.1061/ (ASCE) 1084-0702(2007)12:3(315), 315-324.

Kaneko, Y. (1992). "Modelling of shear-off failure of concrete: Fracture mechanics approach." Ph.D. thesis, Massachusetts Institute of Technology, Cambridge, MA.

Kaneko, Y., Connor, J. J., Triantafillou, T. C., and Leung, C. K. (1993a). "Fracture mechanics approach for failure of concrete shear key. I: Theory." J. Eng. Mech., 10.1061/(ASCE)0733-9399(1993)119:4(681), 681-700.

Kaneko, Y., Connor, J. J., Triantafillou, T. C., and Leung, C. K. (1993b). "Fracture mechanics approach for failure of concrete shear key. II: Verification." J. Eng. Mech., 10.1061/(ASCE)0733-9399(1993)119: 4(701), 701-719.

Kaneko, Y., and Mihashi, H. (1999). "Analytical study on the cracking transition of concrete shear key.” Mater. Struct., 32(3), 196-202.

Kim, T., Kim, Y., Jin, B., and Shin, H. (2007). "Numerical study on the joints between precast post-tensioned segments." Int. J. Concr. Struct. Mater., 19(1E), 3-9.

Kmiecik, P., and Kamiński, M. (2011). "Modelling of reinforced concrete structures and composite structures with concrete strength degradation taken into consideration." Arch. Civ. Mech. Eng., 11(3), 623-636.

Koseki, K., and Breen, J. E. (1983). "Exploratory study of shear strength of joints for precast segmental bridges." Research Rep. 248-1, Center for Transportation Research, Univ. of Texas at Austin, Austin, TX.

Li, G., Yang, D., and Lei, Y. (2013). "Combined shear and bending behavior of joints in precast concrete segmental beams with external tendons." J. Bridge Eng., 10.1061/(ASCE)BE.1943-5592.0000453, 1042-1052.

Poston, R. W., and Wouter, J. P. (1998). "Durability of precast segmental bridges." NCHRP 20-07/Task 092, 〈http://apps.trb.org/cmsfeed/ TRBNetProjectDisplay.asp?ProjectID=1434 (Jun. 20, 2014).

Ramirez, G., MacGregor, R., Kreger, M. E., Roberts-Wollmann, C., and Breen, J. E. (1993). "Shear strength of segmental structures." Proc., Workshop on Behaviour of External Prestressing in Structures, French Construction Association (AFPC), Saint-Rémy-lès-Chevreuse, France, 287-296.

Rombach, G. (1997). "Precast segmental box girder bridges with external prestressing." Proc., Conf. of Actual Problems in Civil Engineering, Saint Petersburg State Univ. of Architecture and Civil Engineering, St. Petersburg, Russia.

Tassios, T. P., and Vintzēleou, E. N. (1987). "Concrete-to-concrete friction." J. Struct. Eng., 10.1061/(ASCE)0733-9445(1987)113:4(832), 832-849.

Turmo, J., Ramos, G., and Aparicio, A. C. (2006a). "Shear strength of dry joints of concrete panels with and without steel fibres: Application to precast segmental bridges." Eng. Struct., 28(1), 23-33.

Turmo, J., Ramos, G., and Aparicio, A. C. (2006b). "Shear strength of match cast dry joints of precast concrete segmental bridges: Proposal for Eurocode 2." Mater. Constr., 56(282), 45-52.

Turmo, J., Ramos, G., and Aparicio, A. C. (2012). "Towards a model of dry shear keyed joints: Modelling of panel tests." Comput. Concr., 10(5), 469-487.

Zhou, X., Mickleborough, N., and Li, Z. (2005). "Shear strength of joints in precast concrete segmental bridges.” ACI Struct. J., 102(1), 3-11. 